\title{
O OLHAR SENSÍVEL QUE AFETA
}

\section{ARTIGO DE REVISÃO}

FREITAS, Kássia Silva de ${ }^{1}$

FREITAS, Kássia Silva de. O olhar sensível que afeta. Revista Científica Multidisciplinar Núcleo do Conhecimento. Ano 05, Ed. 08, Vol. 08, pp. 125-135. Agosto de 2020. ISSN: 2448-0959, Link de acesso: https://www.nucleodoconhecimento.com.br/educacao/olhar-sensivel

\section{RESUMO}

O presente trabalho foi elaborado a partir da monografia "A formação docente como responsabilidade: o olhar sensível e a afetividade na Educação Infantil” a qual foi submetida, no ano de 2018, ao Programa de Pós-Graduação em Educação da PUCRio como requisito parcial para obtenção do título de Especialista em Educação Infantil. O problema discutido tem em voga o olhar sensível do educador para com as crianças pequenas, no qual este é o fio que conduz as experiências, fala, escuta, autonomia e exploração de ambos. A metodologia usada para a escrita foi bibliográfica e de observação do cotidiano de uma instituição privada de educação infantil.

Palavras-chave: olhar sensível, educador, crianças.

\section{INTRODUÇÃO}

O olhar sensível sempre teve suma importância nas discussões vividas ao longo da carreira, porque as vivências cotidianas com as crianças sempre é algo inédito. Partindo desse pressuposto e com a conclusão do Curso de Especialização em Educação Infantil: Perspectivas de trabalho em creches e pré-escolas, que tem como

\footnotetext{
${ }^{1}$ Pós-Graduação em Educação da PUC-Rio como requisito parcial para obtenção do título de Especialista em Educação Infantil. Graduada em Pedagogia pela UERJ Universidade do Estado do Rio de Janeiro.
} 
objetivo promover a reflexão crítica sobre diferentes alternativas na área da educação infantil, tendo a criança, como sujeito histórico, social e cultural procurou-se pensar nesse olhar do educador no ambiente da educação infantil.

Partindo de observações do cotidiano e em diálogo com o referencial teórico, que convoca docentes e não docentes a observar, escutar e compreender sensivelmente seu cotidiano para que, junto às crianças possa provocar-se e estar comprometido nas diversas relações, interações e atividades propostas na (co)construção de conhecimento de ambos, professor e crianças.

Entende-se a criança é sujeito, cria cultura, brinca, dá sentido ao mundo, produz história, recria a ordem das coisas e estabelece uma relação crítica com a tradição. A partir dessa perspectiva, a criança precisa ser pensada como um "outro" que possui potencialidades, peculiaridades e necessidades. Por ser um "outro", cabe a nós adultos, estabelecer diálogos com ela. Diálogo que as considera cidadãs, pessoas em desenvolvimento que produzem cultura e são nela produzidas, que possuem um olhar crítico que vira pelo avesso a ordem das coisas, subvertendo essa ordem.

Nesse movimento de interação, o afeto é um modificador de comportamentos na educação de crianças pequenas quando professores se percebem co-responsáveis por sua caminhada de estruturação e compreensão de si e do mundo. Ou seja, é uma caminhada coletiva em direção à humanização e contra a barbárie.

\section{DESENVOLVIMENTO}

Falar de afeto exige uma responsabilidade tendo em vista superar um viés que simplifica a relação professor-aluno. Semanticamente, de acordo com o Aurélio (2018) afeto "é a disposição de alguém por algo, alguma coisa", porém, na perspectiva teórica abordada no presente trabalho, optou-se por definir o afeto como disponibilidade para tocar o outro.

A partir desse entendimento, é pelo afeto que acontece a construção das relações e interações. É quando nos disponibilizamos a olhar e escutar o outro e, sem dúvida 
esse é um movimento necessário à qualquer profissional que esteja à serviço das crianças pequenas, pois é difícil acreditar sem reagir à essa barbárie presente hoje nessa sociedade egocêntrica e egoísta, exigindo reconhecer a opressão e ter a capacidade de resistência e utopia de uma sociedade e educação justa e sem discriminação, de nenhuma espécie.

Educar contra a barbárie significa trabalhar numa perspectiva de humanização, de resgate de experiência, de conquista da capacidade de ler o mundo, escrevendo a história coletiva, se apropriando das diferentes formas de produção de cultura, criando, expressando, mudando, praticando laços de coletividade e de pertencimento com o reconhecimento das diferenças. Tal movimento se faz necessário na busca de uma sociedade mais igualitária, na qual as ações em busca de perceber os diferentes modos de ser humano visando legitimar o jeito próprio e individual de cada criança ser, sentir e agir no mundo se faz necessário, tendo o diálogo como aliado nesse cotidiano.

\section{SONIA KRAMER- A EDUCAÇÃO COMO RESPOSTA RESPONSÁVEL}

O ser humano se constitui na relação com o outro, na interação social onde as dimensões cognitiva, afetiva e ética estão vinculadas. O significado social e ideológico da criança e o valor social atribuído à infância têm sido objeto de estudo da sociologia. Para a sociologia da infância, as crianças pertencem a categoria social da infância e em seus processos de subjetivação, recriam, nas interações com os adultos e com seus pares, as culturas onde estão inseridas.

Para Kramer (1999), as relações de dependência e poder que se dá entre adulto e criança, tratam de um fator social e não natural. Essas relações estão diretamente relacionadas a razões sociais e ideológicas fortes que incidem no controle e na dominação de grupos. A autora ressalta que, há pouco tempo a infância tinha o significado de ser in-fans (aquele que não fala) e, a partir disso enfatiza a preocupação de como a criança pode adquirir voz e poder em um contexto que, de um lado, infantiliza os sujeitos sociais, empurrando para frente o momento da maturidade e, de outro, os adultiza, jogando para trás a curta etapa da primeira infância? 
Atuar com crianças é uma responsabilidade social. Em seus estudos sobre os processos de escolarização da criança pequena, Kramer (2002) chegou à conclusão de que o que caracteriza o trabalho pedagógico é a experiência com o conhecimento científico, a literatura, as expressões artísticas, históricas e culturais. Sendo assim, acredita que o campo pedagógico é interdisciplinar. Afirma também que essa prática pedagógica e o projeto político pedagógico envolvem sempre o conhecimento e o afeto, saberes e valores, cuidados e atenção, seriedade e sorriso.

O trabalho pedagógico com a criança pequena possui especificidades e exige que estejam presentes nas instituições de educação infantil o cuidado, a atenção, o acolhimento, a alegria, a brincadeira e, nessas práticas as crianças aprendem, interagem, se desenvolvem. Portanto, o saber não pode ser confundido com falta de liberdade, pelo contrário, a liberdade assegura a apropriação e construção do conhecimento.

De acordo com Santos e Corsino, apud Souza (1995) a criança constrói sua subjetividade com os conteúdos sociais e afetivos que o olhar e as palavras do outro Ihe revelam, porque a comunicação verbal é por onde a palavra ganha diferentes significados e se realiza em condição de signo ideológico, pois a palavra do outro é constituinte. Diante disso, acentua-se a importância do olhar atento do professor como o outro que organiza, orienta, acolhe, abriga e dá segurança, permitindo que as crianças tenham espaços para fazer, ousar e criar, pois os processos de socialização são interativos.

Nesse sentido, cada olhar está comprometido com um ponto de vista, porque o que se vê só tem "determinidade" com base na relação que se estabelece com o outro, porque conhecê-lo envolve uma relação de mistura, de identificação, trazendo-o para si com seus referenciais e se distanciando em seguida, reconhecendo assim, a sua singularidade, sua particularidade.

Afetar e ser afetado sensivelmente são modos de promover experiências plurais e reflexivas que se pautem no fazer, no apreciar e no conhecer o mundo e, desse modo, na formação docente pressupõe uma formação em que os diversos conhecimentos 
referentes à criança pequena e a educação infantil possam complementar o trabalho cotidiano. $O$ espaço é também facilitador desse processo e precisa apresentar uma organização do mundo que nos rodeia, no qual favoreça a experimentação de ambos, crianças e adultos, a construir relações saudáveis, aconchegantes e de qualidade.

Portanto, nas relações e interações, a relação adulto-criança será significativa e, independe do gênero desse profissional, é preciso nelas estar por inteiro. Desse modo, entender a educação como resposta responsável significa dar valor a presença do outro no mundo, vinculando-se a ele como alguém que procura estar presente. É dar espaço ao diálogo contínuo e diário do que é vivido, assegurando autoria e autonomia na experiência humana que se constrói entre o conhecimento, o agir ética e a arte. (KRAMER, 2016).

\section{ESCUTA E OLHAR SENSÍVEL}

No trabalho com crianças pequenas uma dinâmica com intuito de afetar e ser afetado implica valorizar o olhar e a escuta como parte do cotidiano e como fonte de pesquisa e de interações entre os sujeitos. Essa é uma prática que constitui a formação de adultos e crianças como constituintes, produtores de sua própria identidade, cultura, linguagem, história, expressões, afeto, socialização, movimentação, imaginário, ludicidade.

Pensar as instituições de educação infantil entendendo-as como lugar onde a vida se concretiza, o conforto e o desconforto da existência ganham forma material e simbólica, a identidade pessoal e social vai se ampliando e os requisitos necessários para a adequada inserção no mundo vão se consolidando de forma a valorizar as singularidades, implica entendê-las como contextos sociais e culturais que valorizam e desafiam suas capacidades intelectuais, criativas, estéticas, expressivas e emocionais dos sujeitos nelas inseridos.

Atuar junto às crianças na perspectiva de um olhar sensível, capaz de oferecer resistência à estereotipia coletiva, requer uma formação dos educadores que contribua para a reconciliação com a própria expressão, Ihe resgatando a palavra, o 
gesto, o traço, as ideias e a autoria, propiciando-lhe a ampliação de possibilidades e a democratização do conhecimento. Olhar sensivelmente requer o exercício de um olhar aberto a perceber, esmiuçar, desvendar, buscar o belo, fazendo emergir o não visto, o que foge e promovendo uma nova relação com a diferença e a diversidade.

Ao experienciar essa formação, consequentemente, o professor se torna um explorador da sensibilidade das crianças, possibilitando que elas se expressem, ampliem e enriqueçam suas experiências e também, aumentem suas possibilidades de interlocução e entendimento da realidade que as cerca, de modo que a vivacidade, a ampliação e o enriquecimento dessas experiências sensíveis, ampliem as suas redes de entendimento e de significação do mundo. Envolve, portanto, uma habilidade técnica, mas também relacional com resposta responsável, ética e comprometida com os sujeitos e com o entorno. (KRAMER; NUNES; CARVALHO, 2016).

O olhar sensível é olhar curioso, descobridor, olhar de quem olha querendo ver além e requer o exercício de um olhar aberto a perceber e partilhar essas experiências significativas a fim de que o repertório de todos seja ampliado e multiplicado, enriquecendo as múltiplas linguagens além de permitir novas associações e construções nas quais a sensibilidade de cada um possa ser assegurada através de sua singularidade em ver o mundo.

Para Falk (2011), o papel do educador é de vital importância na promoção à vida cotidiana da criança esse conjunto de condições de equilíbrio do desenvolvimento, porque este se torna parceiro e proporciona relações significativas, permitindo às crianças total liberdade de ação em todas as situações (FALK, 2011). Neste sentido, Corsino (2012) argumenta que a escola é lugar de trocas e interações, onde se experimenta, brinca, aprende, socializa, produz cultura e constrói sentidos sobre o mundo.

O espaço ganha importância de modo a se tornar um ambiente que precisa ser vivido, experimentado, compreendido, explorado, um espaço habitado onde os limites são transformáveis por quem o habita a partir das experiências neles compartilhadas. $O$ olhar e escutar sensivelmente as crianças, os adultos, os espaços, enfim, todo o 
contexto, é estar aberto as diferenças e reconhecer o ponto de vista e a interpretação do outro. É dar significado a essas perspectivas e conectar-se ao outro. É também assumir a responsabilidade pelo que é compartilhado, é pensar diferente do já pensado. É compreender a responsabilidade de promover e possibilitar a escuta de modo que as linguagens de cada um possam ser negociadas e promovidas por meio do intercambio e da comparação de ideias (RINALDI, 2016).

\section{O DIÁLOGO COMO FONTE DE EXPERIÊNCIA DE CONHECIMENTO DE SI}

Quando a observação faz parte da prática docente ela se torna cada vez mais complexa e reflexiva porque coloca a criança no centro do planejamento e assume-se a responsabilidade de acompanhá-la com atenção e participar da aprendizagem enquanto ela ocorre. Segundo Rinaldi apud Filippini (2016) o papel do adulto é, acima de tudo, escutar, observar e compreender a estratégia que as crianças usam em uma situação de aprendizagem, sendo assim um distribuidor de ocasiões.

Ao estar junto às crianças e observar suas relações e experiências cotidianas, percebe-se que o ser vai se constituindo através da exploração das coisas, porque delas adquire saberes sobre a sua natureza e sua constituição, ou seja, experiência o que é próprio às coisas, já que a experiência se realiza no experimentador e não entre ele e o mundo.

Nessa perspectiva, a prática docente pode ser colocada no cerne da filosofia da relação proposta por Martin Buber em sua obra Eu-tu (1974), pois se trata de uma relação que se dá entre dois corpos físicos que se relacionam a todo o momento e que precisa um do outro para existir e, a palavra é o elo que os une visto que é através dela que o ser se mantém nele mesmo, da qual ele se faz e se situa no mundo com os outros.

Relacionar é reciprocidade. Quando estabelecemos um relacionamento com outrem, procuramos uma reciprocidade da outra parte. Procuramos comunhão com ele, no qual eles nos formam e nossas obras nos edificam, porque passamos a viver numa 
reciprocidade universal. Então atingimos o limite no qual o "entrar-em-relação" reconhece sua própria relatividade, limite que só será revogado se houver uma mesma relatividade.

O que manifesta o crescimento progressivo do mundo do ISSO é a história do indivíduo e a história do gênero humano. Pode-se dizer que, o mundo do ISSO de uma determinada civilização é mais extenso do que o da posterior, apesar das paradas e retrocessos evidentes, percebe-se nitidamente, através da extensão dos conhecimentos da natureza e da proporção tanto das diferenças sociais como das realizações técnicas, na história um aumento evolutivo do mundo do ISSO, progredindo também a capacidade de experimentar e utilizar. (BUBER, 1974).

Sendo assim, o homem explora a superfície das coisas e a experiência, adquirindo delas um saber sobre a sua natureza e sua constituição. A experiência por si se realiza "nele" e não entre ele e o mundo. Quando este mundo da relação é vivido, se obterá três esperas: a vida com a natureza; a vida com os homens; e a vida com os seres espirituais. Em cada esfera desta, vislumbra-se um TU eterno, como um sopro provindo dele, no qual se invoca formas diferentes para cada esfera.

A partir do momento em que se passa a experienciar, a viver situações nestas três esferas, não é possível defini-la como isso ou aquilo e, o movimento que se dá é o de atualizar porque ao realizar EU descubro. EU conduzo a forma para o mundo do ISSO. Porque se a experiência for submetida ao critério da subjetividade, retira-se dela seu mundo empírico, fulgurante e resplandecente, pois do jeito que atuo sobre ela, ela atua sobre mim.

Na medida em que todos os meios são abolidos, acontece o encontro. Porque o TU encontra-se comigo, no ato de meu ser, meu ato essencial, onde o EU é quem me auxilia no contato imediato com ele e domina o ISSO. Na medida em que o homem se contenta com as experiências vividas e as utiliza, vive no passado e seu instante é privado do que o aguarda e permanece diante de nós. Para Buber, "Infeliz aquele que deixa de proferir a palavra-princípio, miserável, porém, aquele que em vez de fazê-lo 
diretamente utiliza um conceito ou um palavreado como se fosse seu nome. (BUBER, 1974, p. 33)".

Segundo Buber (1974), cada TU que existe no mundo terá que se tornar inevitavelmente ISSO, porque precisa de constante atualização e complementação, no qual o ser natural que acaba de se revelar no segredo da ação mútua no presente, terá extraído de si novos sentimentos, pois houve processos que se entrelaçaram desordenadamente numa dualidade: EU-atuando-TU e TU-atuando-EU, onde o homem aprende a se conhecer e a se distinguir.

Como professores, é urgente garantir que os espaços educativos sejam oportunidades para conhecimento do eu, seja adulto ou criança e, consequentemente, de pertencimento, entendendo que o conhecimento do mundo acontece em relação, em comunhão com o conhecimento do eu, onde o cuidado de si deve ser considerado como o momento do primeiro despertar, porque cada um deve cuidar de si no sentido de inquietar-se consigo mesmo e, nesse movimento o corpo é o seu canal de relação consigo e com a sociedade. O mergulho nas possibilidades das coisas e no chamamento do mundo é conduzido pelo olhar, pois a experiência de si que o olhar pode permitir é a confiança, no qual se sustenta a conexão afetiva.

A ação humana consiste neste movimento continuo e perpétuo de reajustamento ou desequilíbrio, na qual as estruturas mentais sucessivas produzem o desenvolvimento como forma de equilíbrio e o progresso é algo que se constitui a cada passo na eterna constituição de ser humano incompleto que a cada dia inventa, transforma o que já se está estabelecido. Ou seja, ele age sobre a realidade e não aprende de forma passiva, mas a partir da diversidade e da riqueza de oportunidades de interação que é oferecido e que oferece cotidianamente, em nossas vidas e nas instituições escolares.

Pensar nas reflexões buberianas das interações cotidianas do ser e o papel do professor como formador em formação é perceber a responsabilidade do quanto esse processo precisa caminhar com o revelar cada vez mais rápido do mundo. É perceber o trabalho com crianças como uma função que precisa ser aprendida, construída. É pensar num espaço dialógico, de concretização da vida social, confronto de pontos de 
vista, de expressão, lugar onde o singular e o coletivo se encontram lugar de formação humana, constituída e constituinte da ação e do pensamento (CORSINO, 2016).

A existência humana é permeada por esse princípio do existir, na qual faz com que o homem que a proferir autenticamente exista. A partir do momento em que o EU-TU mantém a relação de interação, o ISSO se constitui no entrelaço desses encontros, uma reciprocidade dos dois polos envolvidos no dialógico. Para Buber (1974) esse fenômeno se chama inter-humano, no qual é possível a aceitação e a confirmação ontológica desses dois núcleos envolvidos nesse evento da relação.

A partir de Buber (1974), é preciso considerar que tudo o que se alicerça em coisa entre coisas, recebeu por sentido o destino de se transformar continuamente, pois o objeto deve se consumir para se tornar presença, retornando ao elemento de onde veio para ser visto e vivido pelo homem no presente. $O$ aperfeiçoamento da função de experimentação e de utilização se realiza, normalmente, no homem em detrimento de seu poder de relação.

Ser professor é formar-se humanamente como alguém que influencia e foi influenciado pelo mundo das coisas que o cerca, porque toda ação humana tem características intencionais, invencionistas e intuitivas. Formar-se responsavelmente é ter em vista a autoria e a autonomia da criança e do adulto, pois esses processos acontecem em colaboração, porque cada ser é singular e influencia a pluralidade do mundo. Ou seja, ser e estar no mundo requer infinitos caminhos de convivência, porque a infinitude do ser proporciona aprendizados que comporão a totalidade do participante no evento.

\section{CONCLUSÃO}

A formação docente para atuar na Educação Infantil deve ter por finalidade compreender o desenvolvimento integral de crianças de 0 a 5 anos de idade a fim de reconhecê-las, respeitá-las e garantir-lhes o seu direito ao pleno desenvolvimento. Enquanto professora da Educação Infantil, pensar essa profissionalização envolve 
questionamentos, incertezas, descobertas, prazeres e tantas outras maneiras do fazer cotidiano.

Um bom profissional docente, segundo Nóvoa (2017), é aquele que a partir dos conhecimentos obtidos na formação e em formação continuada, prescreve mudanças profundas quando participa socialmente do processo de ensinar, porque com as metamorfoses que a educação passa atualmente, precisa-se de competência para se fazer educação dentro e fora das escolas, pois temos vivido retrocessos quanto à profissionalização docente, onde a desmoralização social e até mesmo, moral da profissão docente conservam cada vez mais interesses privados e não públicos.

Decorrente disso, olhar sensivelmente para o âmbito político requer uma afetividade e o conhecimento que permita a reflexão diária dentro de sala e fora dela. Requer aquisição de informações que impulsionem a observação cautelosa do trabalho cotidiano com as crianças. Nesse sentido é relevante observar interesses, desejos, inquietações, tanto do profissional, quanto das crianças, estabelecendo empatia com o outro. Quando se faz da observação um movimento natural, ela se torna cada vez mais complexa e reflexiva por estar plenamente atenta às crianças e assumindo a responsabilidade de seguir e interagir na aprendizagem enquanto ela ocorre.

\section{REFERÊNCIAS}

BRASIL. Lei de Diretrizes e Bases da Educação Nacional. Lei número 9394, 20 de dezembro de 1996. Edição atualizada até março de 2017. Disponível em: <http://www.planalto.gov.br/ccivil_03/leis/L9394.htm> LDB: Lei de diretrizes e bases da educação nacional. - Brasília: Senado Federal, Coordenação de Edições Técnicas, 2017. 58 p. Acesso em: 15/03/18 às 20h09min.

BRASIL. Política Nacional de Educação Infantil. Ministério de Educação e Desporto. Secretaria de Educação Fundamental. Coordenação de Educação Infantil. Brasília. DF.1994. Disponível em: http://portal.mec.gov.br/seb/arquivos/pdf/pol_inf_eduinf.pdf. Acesso em: 15/03/18 às $20 \mathrm{~h} 21 \mathrm{~min}$. 
BUBER, Martin. Eu e Tu. Tradução do alemão, introdução e notas por Newton Aquiles Von Zuben. Professor da Faculdade da UNICAMP. $2^{a}$ edição revista. Editora Moraes. $\mathrm{SP}$

CORSINO, Patrícia. Infância e Linguagem na obra de Bartolomeu Campos de Queirós: questões para a Educação Infantil. In: KRAMER, Sonia; NUNES, Maria Fernanda; CARVALHO, Maria Cristina (orgs.). Educação Infantil: Formação e Responsabilidade. Campinas, SP: Papirus, 2016, p. 151 - 168.

FALK, Judit. Cuidados pessoais e prevenção. In: FALK, Judit (org.). Abordagem Pikler: Educação Infantil. São Paulo: SP, Omnisciência - Coleção primeira infância: educar de 0 a 6 anos. 2017, p. $16-24$.

FALK, Judit. Educar os três primeiros anos: a experiência de Lóczy. São Paulo: Araraquara - SP. Editora Junqueira\&Marin. 2011, p. $53-62$.

FALK, Judit. Vínculo e Cuidados. In: SOARES, Suzana Macedo (org.). Vínculo, movimento e autonomia. São Paulo: SP, Omnisciência - Coleção primeira infância: educar de 0 a 6 anos. 2017, p. $21-28$.

GANDINI, Lella. Conectando-se por meio dos espaços de cuidado e de aprendizagem. In: EDWARDS, Carolyn; GANDINI, Lella; FORMAN, George (orgs.). As cem linguagens da criança: a experiência de Reggio Emilia em transformação. Porto Alegre: Artes Médicas, 2016. P. 315 - 336.

GUIMARÃES, Daniela. Educação Infantil: espaços e experiências. In: CORSINO, Patrícia. Educação Infantil: cotidiano e políticas. São Paulo: Campinas - SP: Autores Associados - Coleção Educação Contemporânea, 2012, p. 75 - 88.

KRAMER, Sonia. Formação de profissionais de educação infantil: questões e tensões. In: MACHADO, Maria Lúcia de A. (Org.). Encontros e desencontros em educação infantil. São Paulo: Cortez, 2002. 
KRAMER, Sonia. De que professor precisamos para a Educação Infantil? Uma pergunta várias respostas. Revista Pátio Educação Infantil, Ano I, n. 2, ago. - nov., 2003.

KRAMER, Sonia. Eu não estudei tanto tempo para agora me acostumar a gritar: a crianças, as professoras e o currículo. In: PARAÍSO, Marlucy Alves; VILELA, Rita Amélia; SALES, Shirlei Rezende . (org.). Desafios contemporâneos sobre o currículo e a escola básica. 1 ed. Curitiba:CRV,2012,v.1, p.39-51.

KRAMER, Sonia. Formação e Responsabilidade: escutando Mikhail Bakhtin e Martin Bubber. In: KRAMER, Sonia; NUNES, Maria Fernanda; CARVALHO, Maria Cristina (orgs.). Educação Infantil: Formação e Responsabilidade. Campinas, SP: Papirus, 2016, p. $309-329$.

KRAMER, Sonia. Infância e Educação: o necessário caminho de trabalhar contra a barbárie. In: KRAMER, Sonia; LEITE, Maria Isabel; NUNES, Maria Fernanda e GUIMARÃES, Daniela. Infância e Educação Infantil. São Paulo: Papirus, 1999.

KRAMER, Sônia. Propostas pedagógicas ou curriculares: subsídios para uma leitura crítica. IN: Educ. Soc. [online]. Campinas, vol.18, n.60, pp. 15-35. 1997 ISSN 0101-7330. Disponível em: < http://dx.doi.org/10.1590/S0101-73301997000300002>. Acesso em: 13/06/18, às 20h58min.

NOVOA, António. Firmar a posição como professor, afirmar a profissão docente. Cad. Pesqui. [online] .2017, vol.47, n.166, pp.1106-1133. ISSN 0100-1574.

RINALDI, Carlina. A pedagogia da escuta: a perspectiva da escuta em Reggio Emilia. In: EDWARDS, Carolyn; GANDINI, Lella; FORMAN, George (orgs.). As cem linguagens da criança: a experiência de Reggio Emilia em transformação. Porto Alegre: Artes Médicas, 2016. p. 235 - 247.

Enviado: Fevereiro, 2020.

Aprovado: Agosto, 2020. 